\title{
Agreement Between Clinical-Radiographic and Histopathological Diagnoses in Maxillofacial Fibro-Osseous Lesions
}

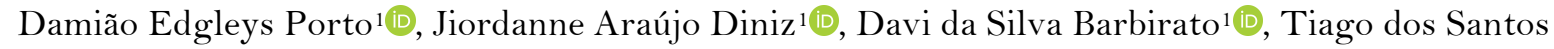 \\ Silva ${ }^{2}$, Richard Ribeiro Alonso de Andrade ${ }^{3}\left[\right.$, Emanuel Sávio de Souza Andrade ${ }^{1}$
}

\footnotetext{
${ }^{`}$ Oral and Maxillofacial Surgery Department, School of Dentistry, University of Pernambuco, Recife, PE, Brazil.

${ }^{2}$ School of Dentistry, University of Pernambuco, Recife, PE, Brazil.

${ }^{3}$ Oral and Maxillofacial Pathology Department, School of Dentistry, University of Pernambuco, Recife, PE, Brazil.
}

Correspondence: Emanuel Savio de Souza Andrade, University of Pernambuco, Oswaldo Cruz University Hospital, Oral and Maxillofacial Surgery Department, Rua Arnóbio Marques, 310, Santo Amaro, Recife, PE, Brazil. 50100-130. E-mail: emanuel.savio@upe.br

Academic Editor: Alidianne Fábia Cabral Cavalcanti

Received: 03 July 2020 / Review: 09 December 2020 / Accepted: 07 January 2021 How to cite: Porto DE, Diniz JA, Barbirato DS, Silva TS, Andrade RRA, Andrade ESS. Agreement between clinical-
radiographic and histopathological diagnoses in maxillofacial fibro-osseous lesions. Pesqui Bras Odontopediatria Clín
Integr. 202 1; 21 :e0156. https://doi.org/10.1590/pboci.2021.075

\begin{abstract}
Objective: To compare the agreement of clinical and radiographic diagnosis with the histopathological diagnosis in fibro-osseous lesions of the jaws. Material and Methods: An analytical and exploratory study was made based on systematic collected data, carried out in the laboratory of surgical pathology of a public Dental School. There were evaluated cases of fibrous dysplasia (FD), cemento-osseous dysplasia (COD) and ossifyng fibroma (OF), diagnosed by clinical, radiographic (panoramic and periapical radiography), and histopathological analysis, in a period of 12 years (from March 2001 to June 2013). Descriptive and inferential statistics (Fisher's exact test) were obtained. Results: Ninety-six cases of FOLs were evaluated. The radiographic aspects of the FOLs studied did not differ significantly $(\mathrm{p}=0.09)$. Radiolucent lesions were the least frequent, corresponding to approximately $13.5 \%$ of radiographic findings. Mixed lesions and radiopaques were more present, how they were COD and FD, respectively. The more aggressive variation of OF (Juvenile Ossifying Fibroma - JOF) was less frequent among the pathologies evaluated. In approximately $61.46 \%$ of the cases clinical and radiographic diagnosis were confirmed by histopathological diagnosis of FOLs. The highest agreement and the highest disagreement were observed in COD cases ( $40.7 \%$ and $62.2 \%$, respectively). Conclusion: FOLs of the maxillaries represent a group of lesions in which the establishment of the clinical and radiographic diagnosis supported by the histopathological confirmation is critical and challenging.
\end{abstract}

Keywords: Pathology, Oral; Surgery, Oral; Neoplasms, Fibrous Tissue. 


\section{Introduction}

Fibro-osseous lesions (FOLs) are a group of pathologies represented by hamartomas, dysplastic and reactive processes and neoplasias [1]. The main histopathological finding is the reinstatement of the bone tissue by collagen, with the presence of fibroblasts and mineralizations [2,3]. Osteoblast rimming and osteoclast-like giant cells may be present [4]. However, clinical, and radiological evaluations are fundamental for the definitive diagnosis since they differ due to etiology and clinical behavior and some FOLs are histologically diagnosable [5]. Some of those pathologies are exclusive of the jaws and others may develop in bones of other regions [6]. Certain conditions are quite ordinary, while others are scarce [7].

Radiographically, FOLs can present as radiolucent, mixed (radiolucent and radiopaque) or radiopaque. The lesions may be well outlined or not, interacting with the surrounding bone. Bone expansion may or may not arise, such as tooth dislocation and root resorption [2,8,9]. Histologically, FOLs are made of mineralized tissue (bone, lamellar tissue, or cement) and fibrous connective tissue with foci of mineralization [9,10]. Classification of FOLs remained a challenging and controversial theme over the years, giving rise to many classifications [1,6,11-21]. Among them, Waldron's classification [22], slightly modified by Brannon and Fowler [12], it became the most recognized and applied in practice [5].

The World Health Organization (WHO) regards the designation "fibro-osseous" in the current classification of head and neck tumors, including ossifyng fibroma (OF), fibrous dysplasia (FD), familial gigantiform cementum (FGC) and cemento-osseous dysplasia (COD) [14]. Diagnosis and treatment of FOLs are controversial in view of the histological similarities between them. Grouping those pathologies is not appropriate because of the different pathophysiologies [5,23]. Hence, this study aimed to compare the agreement of clinical and radiographic diagnosis with the histopathological diagnosis in FOLs of the jaws, an approach that even today is still little discussed and of relevant importance in the study of diseases affecting the maxillofacial region.

\section{Material and Methods}

Study Design and Data Collection

An analytical and exploratory study was made based on systematic collected data descriptive and quantitative, carried out in the laboratory of surgical pathology of a public Dental School in Brazil. There were evaluated cases of FD, COD and OF, diagnosed by clinical, radiographic (panoramic and periapical radiography), and histopathological analysis, in a period of 12 years (from March 2001 to June 2013).

Cases with limited description, with histopathological diagnosis of benign FOLs were not included in the comparative analysis with clinical diagnosis. Histopathological diagnoses did not belong to the FOL group they were categorized as "Others". Focal, periapical, and florid variants were grouped into the COD category. For these cases, two nominal variables titled clinical-radiographic diagnosis and histopathological diagnosis were categorized. The level of agreement between the two was calculated by simple Kappa's test. The interpretation of the Kappa coefficient was based on the following criterion: < o, no agreement; 0 to 0.19 , weak agreement; 0.20 to 0.39 , reasonable agreement; 0.40 to 0.59 , moderate agreement; 0.60 to 0.79 , substantial agreement, and 0.80 to 1, excellent agreement [24]. Clinical-radiographic diagnosis and histopathological diagnosis were classified according to the current classification of WHO [14].

Data Analysis 
The databases were generated and analyzed in Microsoft Excell 2018 software (Office 365, Microsoft, Redmond, WA, USA) and IBM SPSS, version 21.0 (IBM Corp., Armonk, NY, USA). Descriptive and inferential statistics (Fisher's exact test) were obtained. Statistical significance level of $\mathrm{p} \leq 0.05$ was considered statistically significant for all parameters. After the descriptive analysis, the concordance between the clinical and histopathological diagnoses were verified by the statistical Kappa test.

Ethical Clearance

This study was approved by the Human Research Ethics Committee of University of Pernambuco with the number 21150314.4 .0000.5207 and was conducted in accordance with the principles of the Declaration of Helsinki.

\section{Results}

Ninety-six cases of FOLs documented between March 2001 and June 2013 were evaluated. The radiographic aspects of the FOLs studied did not differ significantly $(p=0.09)$. Radiolucent lesions were the least frequent, corresponding to approximately $13.5 \%$ of radiographic findings. Mixed lesions and radiopaques were more present, how they were COD and FD, respectively. The more aggressive variation of OF (JOF) was less frequent among the pathologies evaluated (Table 1).

Table 1. Radiographic aspects of FOLs in relation to clinical diagnosis.

\begin{tabular}{|c|c|c|c|c|c|c|c|c|c|c|}
\hline \multirow{3}{*}{ Radiographic Aspects } & \multicolumn{8}{|c|}{ Clinical Diagnosis } & \multirow{3}{*}{ p-value } & \multirow{3}{*}{$\begin{array}{l}\text { Total } \\
\text { N }(\%)\end{array}$} \\
\hline & \multicolumn{2}{|c|}{ FD } & \multicolumn{2}{|c|}{ COD } & \multicolumn{2}{|c|}{ OF } & \multicolumn{2}{|c|}{ JOF } & & \\
\hline & $\mathrm{N}$ & $\%$ & $\mathrm{~N}$ & $\%$ & $\mathrm{~N}$ & $\%$ & $\mathrm{~N}$ & $\%$ & & \\
\hline Radiolucid & 4 & 25.0 & 3 & 16.7 & 3 & 16.7 & 3 & 25.0 & & $13(100.0)$ \\
\hline Radiopaque & 11 & 19.2 & 23 & 42.3 & 5 & 7.7 & $\mathrm{O}$ & 0.0 & 0.09 & 39 (100.0) \\
\hline Mist & 14 & 19.7 & 21 & 30.3 & 6 & 7.6 & 3 & 4.5 & & $44(100.0)$ \\
\hline Total & 29 & 30.3 & 47 & 48.9 & 14 & 14.6 & 6 & 6.2 & & $96(100.0)$ \\
\hline
\end{tabular}

FD = Fibrous Dysplasia; COD = Cemento-Osseous Dysplasia; OF = Ossifyng Fibroma; JOF = Juvenile Ossifying Fibroma.

The occurrence of different FOLs diagnosed by histopathological examination differed significantly between the mandible and the maxilla $(\mathrm{p}<0.05)$. On the mandible, $17.7 \%$ of the FOLs were diagnosed as COD. On the maxilla, FD was more frequent among the pathologies investigated, however COD, OF and JOF were also quite evident in this region (Table 2 ).

Table 2. Histopathological diagnosis of FOLs in the jaws.

\begin{tabular}{lcccccccccccc}
\hline \multirow{2}{*}{ Location } & \multicolumn{1}{c}{ FD } & \multicolumn{4}{c}{ COD } & \multicolumn{1}{c}{ OF } & \multicolumn{2}{c}{ JOF } & \multicolumn{2}{c}{ Other } & p-value & Total \\
& $\mathrm{N}$ & $\%$ & $\mathrm{~N}$ & $\%$ & $\mathrm{~N}$ & $\%$ & $\mathrm{~N}$ & $\%$ & $\mathrm{~N}$ & $\%$ & \\
\hline Mandible & 6 & 6.3 & 17 & 17.7 & 8 & 8.3 & 1 & 1.1 & 17 & 17.7 & 0.00 & $49(100.0)$ \\
Maxilla & 10 & 10.4 & 7 & 7.3 & 5 & 5.2 & 5 & 5.2 & 20 & 20.8 & $47(100.0)$ \\
\multicolumn{1}{c}{ Total } & 16 & 16.7 & 24 & 25 & 13 & 13.5 & 6 & 6.3 & 37 & 38.5 & & $96(100.0)$ \\
\hline
\end{tabular}

$\overline{\mathrm{FD}}=$ Fibrous Dysplasia; COD = Cemento-Osseous Dysplasia; OF = Ossifyng Fibroma; JOF = Juvenile Ossifying Fibroma.

In approximately $61.46 \%$ of the cases (59:96) clinical and radiographic diagnosis were confirmed by histopathological diagnosis of FOLs. The highest agreement and the highest disagreement were observed in COD cases $(40.7 \%$ and $62.2 \%$, respectively) (Table 3 ). The agreement observed between clinical-radiographic and histopathological diagnosis were classified as moderate $($ Kappa $=0.5)$. 
Table 3. Agreement between clinical-radiographic and histopathological diagnosis of FOLs.

\begin{tabular}{lccccc}
\hline \multicolumn{1}{c}{ Fibro-Osseous Lesions } & \multicolumn{2}{c}{ Concordant } & \multicolumn{2}{c}{ Discordant } & p-value \\
& $\mathrm{N}$ & $\%$ & $\mathrm{~N}$ & $\%$ & \\
\hline Fibrous Dysplasia & 16 & 27.1 & 13 & 35.1 & 0.04 \\
Cemento-Osseous Dysplasia & 24 & 40.7 & 23 & 62.2 & \\
Ossifyng Fibroma & 13 & 22.0 & 1 & 2.7 & \\
Juvenile Ossifying Fibroma & 6 & 10.2 & 0 & 0.0 & \\
\multicolumn{1}{c}{ Total } & 59 & 100.0 & 37 & 100.0 & \\
\hline
\end{tabular}

\section{Discussion}

FOLs of the jaws are pathologies hard to diagnose, regarding their radiographic and microscopic similarities, and different etiologies and clinical behavior [5,9]. Final diagnosis of FOLs of the jaws depends on the correlation among the history of the current disease, clinical and radiographic characteristics of the lesion, intraoperative observations, and histopathological findings [8]. The most frequent FOL in this research was COD. This result resembles those of Kato et al. [2] and agrees with the findings in the literature that consider OF or FD as the main FOLs [4,25,26]. Studies based only on histopathological results may underestimate the occurrence of COD, whereas its diagnosis also includes clinical data and radiographic findings.

Radiopaque and mixed lesions were predominant in the clinical and radiographic diagnosis of FOLs, as well as in the study by Kato et al. [2] Radiographic features of OF and JOF cases are, in general, radiolucent with radiopaque sites, also described as mixed $[5,8,12,27]$. This finding was confirmed in OF cases, however, JOF also presented as radiolucent lesions. Radiographic aspect common to FD is radiopacity, similar to "ground-glass" appearance [28] that was observed in present study. Although studies show that COD predominantly presents mixed radiographic features [3,6,9], in the present study we identified a higher frequency of radiopaque cases, similar to the findings of Phattarataratip et al. [26].

Mandibular region seems to be indeed the site most affected by FOLs $[7,8,27]$. FD and JOF were more prevalent in the maxilla, as they were the results of Phattarataratip et al. [26], moreover discordant to those of Muwazi and Kamulegeya [4] and Akashi et al. [28] The highest prevalence of COD was observed in the mandible, as well as in the study published by Kato et al. [2], but the same was not observed by Lasisi et al. [25] and Muwazi and Kamulegeya [4] who did not find a statistically significant difference in the prevalence of this lesion between the jaws. As well as the results of Lasisi et al. [25] and Muwazi and Kamulegeya [4], OF mainly affected the mandible.

When comparing the assertiveness indexes of clinical and histopathological diagnosis, in most studies FOLs are not mentioned [23,29]. The agreement between clinical and histopathological diagnoses of bone lesions observed by Mendez et al. [23] were 75\%. Souza et al. [20] suggest FOLs are the pathologies of lesser coincidence of comparative results between clinical and histopathological diagnosis. Kato et al. [2] points out the greater occurrence of FOLs diagnostic error because of the difficulty of excluding differential diagnoses by identifying unique characteristics of the lesion, which guarantees the final diagnosis.

In this study was observed that the FOLs group are quite confused with other lesions, however, due to the lack of studies that approached the agreement between clinical and histopathological diagnosis in FOLs directly, we had few parameters to compare directly with other authors that is characterized as a limitation of research. Akashi et al. [28] reported a concordance of approximately 72.73\% (8:11) of clinical diagnosis of FOLs. In the present study, $61.46 \%$ of cases (59:96) diagnosed clinically and radiographically were confirmed by histopathological analysis. Another weakness of this study was the filling the specimen referral form, in which there was often a lack of details that allowed the pathologist to associate the clinical and microscopic 
characteristics to arrive at a more effective diagnosis, classifying FOL in a generic way as BFOL, same weakness pointed out by Chen et al. [29].

Regarding the confirmation of the histopathological diagnosis by clinical and radiographic examination and biopsy quality, the findings of this study corroborate Abramovitch and Rice [27] and Ahmad and Gaalaas [7] when they reiterate the need for more detailed imaging and clinical exams in more detail, because histopathological diagnosis alone is not definitive and that diagnostic errors can emerge when that data is not carefully considered. A histopathological diagnosis without radiographic correlation is only possible if the biopsy specimen includes the interface between adjacent lesional and normal tissue and may have therapeutic implications and prognostic repercussions [5].

\section{Conclusion}

FOLs of the maxillaries represent a group of lesions in which the establishment of the clinical and radiographic diagnosis supported by the histopathological confirmation is critical and challenging. OF was the diagnosis with the highest percentage of agreement. It is emphasized the need for more studies that approach the subject in order to optimize the diagnosis and treatment of FOLs.

\section{Authors' Contributions}

DEP (D) https://orcid.org/0000-0002-7000-7887 Conceptualization, Writing - Original Draft and Writing - Review and Editing.

JAD (iD https://orcid.org/0000-0001-6782-8345 Writing - Review and Editing.

DSB (iD https://orcid.org/0000-0003-0527-6092 Formal Analysis and Data Curation.

TSS (D) https://orcid.org/0000-0003-0591-3311 Methodology, Investigation and Data Curation.

RRAA (iD https://orcid.org/0000-0002-5269-0774 Methodology, Investigation, Data Curation and Writing - Review and Editing.

ESSA (D) https://orcid.org/0000-0003-2165-4217 MethodologyWriting - Review and Editing and Supervision.

All authors declare that they contributed to critical review of intellectual content and approval of the final version to be published.

\section{Financial Support}

This study was financed in part by the Coordenação de Aperfeiçoamento de Pessoal de Nível Superior - Brasil (CAPES) - Finance Code 001 .

\section{Conflict of Interest}

The authors declare no conflicts of interest.

\section{Data Availability}

The data used to support the findings of this study can be made available upon request to the corresponding author.

\section{References}

[1] Eversole R, Su L, Elmofty S. Benign fibro-osseous lesions of the craniofacial complex. A 388 review. Head Neck Pathol 2008; 2(3):177-202. https://doi.org/10.1007/s12105-008-0057-2

[2] Kato CNAO, Nunes LFM, Chalub LLFH, Etges A, Aparecida Silva T, Mesquita RA. Retrospective study of 383 cases of fibro-osseous lesions of the jaws. J Oral Maxillofac Surg 2018; 76(11):2348-59. https://doi.org/10.1016/j.joms.2018.04.037

[3] Neville BW, Damm DD, Allen CM, Chi A. Oral and Maxillofacial Pathology. $4^{\text {th }}$. ed. St-Louis: Elsevier; 2016.

[4] Muwazi LM, Kamulegeya A. The 5-year prevalence of maxillofacial fibro-osseous lesions in Uganda. Oral Dis 2015; 21(1):79-85. https://doi.org/10.1111/odi.12233

[5] Mainville GN, Turgeon DP, Kauzman A. Diagnosis and management of benign fibro-osseous lesions of the jaws: a current review for the dental clinician. Oral Dis 2017; 23(4):440-50. https://doi.org/10.1111/odi.12531

[6] El-Mofty S. Fibro-osseous lesions of the craniofacial skeleton: an update. Head Neck Pathol 2014; 8(4):432-44. https://doi.org/10.1007/s12105-014-0590-0

[7] Ahmad M, Gaalaas L. Fibro-osseous and other lesions of bone in the jaws. Radiol Clin North Am 2018; 56(1):91-104. https://doi.org/10.1016/j.rcl.2017.08.007 
[8] MacDonald DS. Maxillofacial fibro-osseous lesions. Clin Radiol 2015; 70(1):25-36 https://doi.org/10.1016/j.crad.2014.06.022

[9] Рогожин ДВ, Бертони Ф, Ванель Д, Гамбаротти М, Риги А, Булычева ИВ, et al. Benign fibro-osseous lesions of the craniofacial area in children and adolescents: a review. Arkh Patol 2015; 77(4):63-70. https://doi.org/10.17116/patol201577463-70

[10] Shmuly T, Allon DM, Vered M, Chaushu G, Shlomi B, Kaplan I. Can differences in vascularity serve as a diagnostic aid in fibro-osseous lesions of the jaws? J Oral Maxillofac Surg 2017; 75(6):1201-8. https://doi.org/10.1016/j.joms.2016

[11] Barnes L, Eveson JW, Reichart P, Sidransky D. World Health Organization Classification of Tumours: Pathology and Genetics of Head and Neck Tumours. 4th ed. Lyon: IARC Press; 2005.

[12] Brannon RB, Fowler CB. Benign fibro-osseous lesions: A review of current concepts. Adv Anat Pathol 2001; 8(3):12643. https://doi.org/10.1097/00125480-200105000-00002

[13] de Norhona Santos Netto J, Machado Cerri J, Miranda AM, Pires FR. Benign fibro-osseous lesions: clinicopathologic features from 143 cases diagnosed in an oral diagnosis setting. Oral Surg Oral Med Oral Pathol Oral Radiol 2013; 115(5):56-65. https://doi.org/10.1016/j.oooo.2012.05.022

[14] El-Naggar AK, Chan JKC, Grandis JR, Takata, Slootweg PJ. World Health Organization Classification of Head and Neck Tumours. $4^{\text {th }}$ ed. Lyon: IARC Press; 2017.

[15] Eversole LR. Craniofacial fibrous dysplasia and ossifying fibroma. Oral Maxillofac Surg Clin North Am 1997; 9(1):625-42. https://doi.org/10.1016/j.oooo.2012.05.022

[16] Makek MS. So called "fibro-osseous lesions" of tumorous origin: biology confronts terminology. J Craniomaxillofac Surg 1987; 15(3):154-67. https://doi.org/10.1016/s1010-5182(87)80040-9

[17] Mccarthy EF. Fibro-osseous lesions of the maxillofacial bones. Head Neck Pathol 2013; 7(1):5-10. https://doi.org/10.1007/s12105-013-0430-7

[18] Slootweg PJ, Müller H. Differential diagnosis of fibro-osseous jaw lesions: a histological investigation on 30 cases. J Craniomaxillofac Surg 1990; 18(5):2 10-14. https://doi.org/10.1016/s1010-5182(05)80413-5

[19] Speight PM, Carlos R. Maxillofacial fibroosseous lesions. Curr Diagn Pathol 2006; 12(1):1-10. https://doi.org/10.1016/j.cdip.2005.10.002

[20] Souza JGS, Soares LA, Moreira G. Agreement between clinical and histopathological diagnoses of oral lesions diagnosed in clinic university. Rev Odontol UNESP 2014; 43(1):30-5. https://doi.org/10.1590/S1807-25772014000100005

[21] Waldron CA. Fibro-osseous lesions of the jaws. J Oral Maxillofac Surg 1985; 49(4):249-62. https://doi.org/10.1016/0278-2391(85)90283-6

[22] Waldron CA. Fibro-osseous lesions of the jaws. J Oral Maxillofac Surg 1993; 51(1):828-35. https://doi.org/10.1016/s0278-2391(10)80097-7

[23] Mendez M, Haas AN, Rados PV, Sant'Ana Filho M, Carrard VC. Agreement between clinical and histopathologic diagnoses and completeness of oral biopsy forms. Braz Oral Res 2016; 30(1):94-102. https://doi.org/10.1590/1807-3107BOR-2016.vol30.0094

[24] Landis JK, Koch GG. The measurement of observer agreement for categorical data. Biometrics 1977; 33(1):159-74. https://doi.org/10.2307/2529310

[25] Lasisi TJ, Adisa AO, Olusanya AA. Fibro-osseous lesions of the jaws in Ibadan, Nigeria. Oral Health Dent Manag 2014; 13(1):41-4. https://doi.org/10.2307/2529310

[26] Phattarataratip E, Pholjaroen C, Tiranon PA. Clinicopathologic analysis of 207 cases of benign fibro-osseous lesions of the jaws. Int J Surg Pathol 2014; 22(1):326-33. https://doi.org/10.1177/1066896913511985

[27] Abramovitch K, Rice DD. Benign fibro-osseous lesions of the jaws. Dent Clin North Am 2016; 60(1):167-93. https://doi.org/10.1016/j.cden.2015.08.010

[28] Akashi M, Matsuo K, Shigeoka M, Kakei Y, Hasegawa T, Tachibana A, et al. A case series of fibro-osseous lesions of the jaws. Kobe J Med Sci 2017; 63(3):73-9. https://doi.org/10.1177/1066896913511985

[29] Chen S, Forman M, Sadow PM, August M. The diagnostic accuracy of incisional biopsy in the oral cavity. J Oral Maxillofac Surg 2016; 74(5):959-64. https://doi.org/10.1016/j.joms.2015.11.006 